\title{
LOWERING THE SINTERING TEMPERATURE OF BARIUM STRONTIUM TITANATE BULK CERAMICS BY BARIUM STRONTIUM TITANATE-GEL AND $\mathrm{BaCu}\left(\mathrm{B}_{2} \mathrm{O}_{5}\right)$
}

\author{
"UWE GLEISSNER*, CHRISTOF MEGNIN*, MANUEL BENKLER*, DANIEL HERTKORN*, \\ HENDRIK C. ELSENHEIMER*, KATRIN SCHUMANN*, FLORIAN PAUL*, THOMAS HANEMANN*,** \\ *University of Freiburg, IMTEK, Laboratory for Materials Processing, \\ Georges-Köhler-Allee 102, 79110 Freiburg, Germany \\ **Karlsruhe Institute of Technology (KIT), Institute for Applied Materials - Materials Process Technology, \\ Hermann von Helmholtz Platz 1, 76344 Eggenstein-Leopoldshafen, Germany
}

"E-mail: uwe.gleissner@imtek.uni-freiburg.de

Submitted November 2, 2015; accepted February 7, 2016

\begin{abstract}
Keywords: Barium strontium titanate (BST), Ferroelectric ceramics, Mixed oxide route, Sol-gel route, Sintering temperature, $\mathrm{BaCu}\left(\mathrm{B}_{2} \mathrm{O}_{5}\right)(\mathrm{BCB})$, Liquid phase

In this paper the influence of barium strontium titanate (BST) xerogel as a sinter additive and $\mathrm{BaCu}\left(\mathrm{B}_{2} \mathrm{O}_{5}\right)(\mathrm{BCB})$ as a liquid phase sintering aid on the sintering behavior of BST bulk ceramics is investigated. BST as well as BCB powders were synthesized via a mixed oxide route and BST gel via a sol-gel process. Compared to pure BST bulk ceramics, BST gel reduces the sintering start (onset temperature) by up to $174^{\circ} \mathrm{C}$ and increases the density for a sintering temperature of $1200^{\circ} \mathrm{C}$. By adding $B C B$ to the BST powder the sintering was completed much faster and the onset temperatures were reduced by $281{ }^{\circ} \mathrm{C}$ and $312^{\circ} \mathrm{C}$ for $1 \mathrm{~mol} . \%$ and $2.5 \mathrm{~mol} . \%$, respectively. With $2.5 \mathrm{~mol} . \% \mathrm{BCB}$, the highest density of $96 \%\left(5.41 \mathrm{~g} \cdot \mathrm{cm}^{-3}\right) \mathrm{was}$ achieved at $950^{\circ} \mathrm{C}$.
\end{abstract}

\section{INTRODUCTION}

Ferroelectric materials are a sub-group of dielectric materials that show unique physical properties, like piezoelectric or pyroelectric behavior [1]. Furthermore, some of these materials exhibit a change in their relative permittivity $\left(\varepsilon_{\mathrm{r}}\right)$ with respect to the applied field and are therefore called tunable ferroelectrics. These materials can be used as capacitors in mobile communication systems and wireless techniques such as WiFi, Bluetooth or RFID [2-4]. The operation of many and different wireless communication techniques demands a higher bandwidth or the use of multiband systems [5]. The advantages of tuneable ferroelectrics compared to micro electro mechanical systems (MEMS) are lower power consumption, fast response times, and high Q-values [6-8].

Barium strontium titanate $\left(\mathrm{Ba}_{\mathrm{x}} \mathrm{Sr}_{1-\mathrm{x}} \mathrm{TiO}_{3}, \mathrm{BST}\right)$ is such a ferroelectric material and has been the subject of recent research $[7,9,10,11]$. In this report, the composition $\mathrm{Ba}_{0.6} \mathrm{Sr}_{0.4} \mathrm{TiO}_{3}$ (BST60) is used, which is known for its high tunability [12]. Dielectric properties of BST can be modified by varying the composition and doping of foreign atoms [13]. There are several production methods for BST like the mixed oxide route (MOX), precipitation, and the sol-gel process [1].
In order to use tuneable ferroelectrics in metalinsulator-metal (MIM)-structures, they have to be contacted by metal electrodes on both sides. The metal electrodes have to be deposited onto the ceramic in the green state and are sintered together with the ceramic material. Typical sintering temperatures for BST are in the range of $1250^{\circ} \mathrm{C}$ [14] or $1350^{\circ} \mathrm{C}$ [15], depending on the required density. This leads to a degradation of the metal electrodes and thereby to a decrease of the performance and quality of the corresponding device or application. Therefore, it is necessary to lower the sintering temperature, which then enables the fabrication of MIM structures and the application of LTCC (lowtemperature co-fired ceramic) processes.

The sintering temperature of ceramics can be decreased by adding sintering or liquid phase aids. However, despite lowering the sintering temperature, these additives can have a negative impact on ferroelectric properties [16]. In this investigation, BST gel is used as a sintering aid, due to the formation of ceramic particles with a high specific surface area. The high specific area shows an increased sinter activity and, thus, lower sintering temperatures. The organic compounds of BST gel are burned out completely during the sintering process. As a result, no secondary phase is introduced to the BST and no negative influence on the ferroelectric 
properties occurs. As a liquid phase aid $\mathrm{BaCu}\left(\mathrm{B}_{2} \mathrm{O}_{5}\right)$ (BCB) was used, which has low toxicity $[17,18]$ and is known to lower the sintering temperature of BST down to $950^{\circ} \mathrm{C}$ [15]. Additionally, a combination of BST gel and $\mathrm{BCB}$ was investigated. Table 1 gives an overview of liquid phase sintering additives for BST reported in the literature, the corresponding sintering temperatures and compositions of the BST.

In the next section the experimental part will be described, followed by results and discussion of the experiments and investigated materials and samples. At the end, a short summary, accompanied by the possibility of future applications and prospects, will be presented.

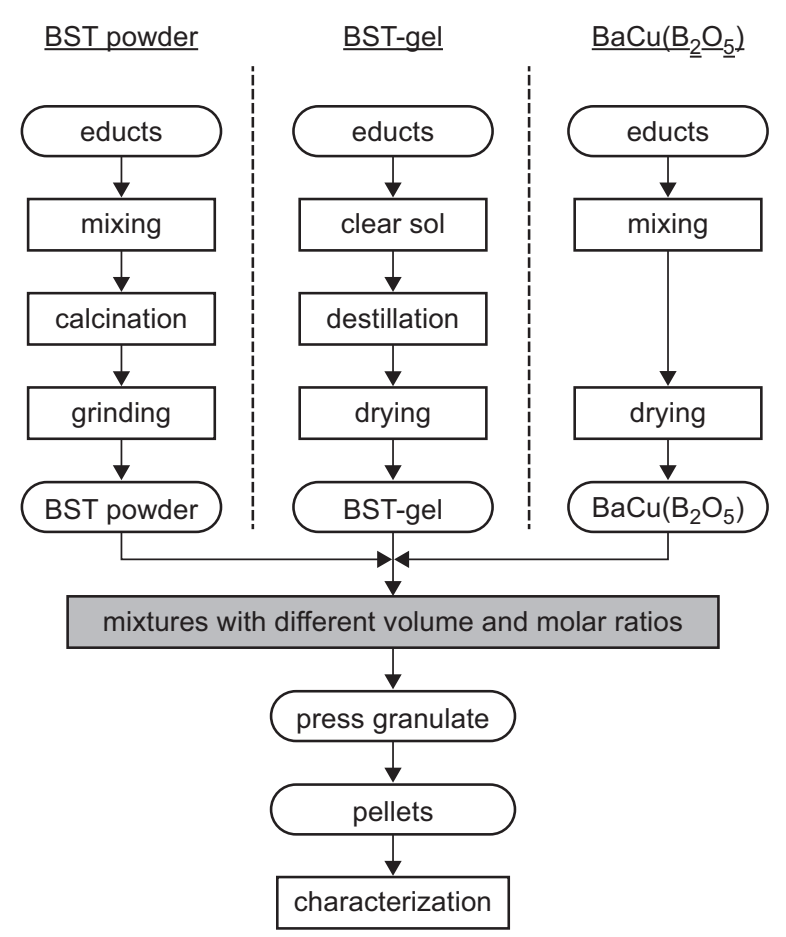

Figure 1. Synthesis routes of BST powder, BST gel and BCB.

\section{EXPERIMENTAL}

Figure 1 shows the applied synthesis routes for BST powder, BST gel, and BCB. BST and BCB powder were synthesized via the mixed oxide route [33]. The BST gel was obtained via a sol-gel process [33]. Subsequently the materials were mixed in different volumetric and molar ratios, granulated, and then pressed to pellets.

\section{Synthesis of materials}

\section{BST-powder}

The BST powder was mixed out of the educts $\mathrm{BaCO}_{3}\left(\mathrm{BDH}\right.$ Prolabo, $99 \%$ ), $\mathrm{SrCO}_{3}$ (Alfa Aesar, $99 \%$ ), and $\mathrm{TiO}_{2}$ (Evonik, p25) in the stoichiometric ratio of $\mathrm{Ba}_{0.6} \mathrm{Sr}_{0.4} \mathrm{TiO}_{3}$. To achieve high homogeneity, the starting materials were mixed using a planetary mill at $200 \mathrm{rpm}$ for $1 \mathrm{~h}$ (PM 400/2, Retsch) with 2-Propanol as the dispersing medium and $\mathrm{ZrO}_{2}$ grinding balls (diameter $1.6-1.8 \mathrm{~mm}$ ). The mixture was then dried in a two-step process using a rotary evaporator (LABOROTA 4003, Heidolph). In the first step 2-Propanol was removed using a water bath at $60^{\circ} \mathrm{C}$ under 165 mbar pressure to prevent 2-Propanol from boiling. In the second step, the temperature was increased to $75^{\circ} \mathrm{C}$ and the pressure was lowered to 75 mbar to remove last solvent residues. Afterwards, the grinding balls were removed by sieving. The dried powder was calcined using a ceramic crucible $\left(\mathrm{Al}_{2} \mathrm{O}_{3}\right)$ in a chamber furnace (CWF 1300, Carbolite) in ambient air. Doing this, the powder was heated to $1100^{\circ} \mathrm{C}$ for 2 hours at a rate of $5 \mathrm{~K} \cdot \mathrm{min}^{-1}$ and subsequently cooled down at the same rate. After calcination, the powder was sieved again, which resulted in ceramic yield of $98 \%$. To reduce the particle size the powder was ground using a universal roller (UR-1/400-FU-EH, GERMATEC $\mathrm{GmbH}$ ) for $91 \mathrm{~h}$ at $75 \mathrm{rpm}$. 2-Propanol again was used (volume ratio powder:2-Propanol 1:10)

Table 1. Summary of reported liquid sintering aids, the corresponding sintering temperatures and material compositions of BST.

\begin{tabular}{|c|c|c|c|}
\hline Additive & Sintering temperature $\left({ }^{\circ} \mathrm{C}\right)$ & Material composition & Reference \\
\hline $\mathrm{Ag}$ & 960 & BST75 & [19] \\
\hline $\mathrm{BaCuB}_{2} \mathrm{O}_{5}$ & 950 & BST60 & {$[17,18]$} \\
\hline $\mathrm{B}_{2} \mathrm{O}_{3}-\mathrm{Li}_{2} \mathrm{CO}_{3}$ & 850 & BST60 & {$[20]$} \\
\hline $\mathrm{B}_{2} \mathrm{O}_{3}$ & $<1150$ & BST70 & {$[21]$} \\
\hline $\mathrm{Bi}_{2} \mathrm{O}_{3}-\mathrm{CuO}$ & 975 & BST60 & {$[16]$} \\
\hline $\mathrm{CuBi}_{2} \mathrm{O}_{4}$ & 1100 & BST60 & {$[22]$} \\
\hline $\mathrm{CuO}$ & 1150 & BST50 & {$[23]$} \\
\hline Glass frit & 900 & BST45 & [9] \\
\hline $\mathrm{Ba}-\mathrm{Sr}-\mathrm{Ti}-\mathrm{Pb}-\mathrm{B}-\mathrm{Si}-\mathrm{O}-\mathrm{Gel}$-glass & $<1000$ & BST60 & {$[24]$} \\
\hline Bi-Li-glass & 920 & BST40/50/55/60 & {$[25]$} \\
\hline $\mathrm{LiO}_{2}$ & $<900$ & BST60/55 & {$[26-28]$} \\
\hline $\mathrm{Li}_{2} \mathrm{CO}_{3}$ & 900 & BST50 & [29] \\
\hline $\mathrm{Zn}-\mathrm{B}-\mathrm{Si}-\mathrm{O}$ & 975 & BST70 & {$[30]$} \\
\hline $\mathrm{ZnBO}$ & 1100 & BST50 & {$[15,29,31,32]$} \\
\hline
\end{tabular}


as a dispersing medium along with $\mathrm{ZrO}_{2}$ grinding balls (volume ratio powder:balls 1:5) for better grinding. Afterwards the resulting powder was dried as described above and the balls were removed.

\section{BST-gel}

The BST gel was synthesized in a temperature controlled glass reactor using the sol-gel route [33]. First, barium acetate (Sigma Aldrich, > $99 \%$ ) and strontium acetate (Sigma Aldrich, $97 \%$ ) were dissolved in acetic acid at room temperature. After 30 minutes of stirring titanium(IV) isopropoxide, ethylene glycol, and, DIwater were added. The corresponding molar equivalents are given in Table 2 .

Table 2. Weighed-in quantities, volumes, and molar equivalents of the educts for the BST-gel.

\begin{tabular}{lccc}
\hline & $\begin{array}{c}\text { Weighed-in } \\
\text { quantity }(\mathrm{g})\end{array}$ & $\begin{array}{c}\text { Volume } \\
(\mathrm{ml})\end{array}$ & $\begin{array}{c}\text { Mol } \\
\text { equivalent }\end{array}$ \\
\hline barium acetate & 3.83 & 1.55 & 0.6 \\
strontium acetate & 2.24 & 1.07 & 0.4 \\
titanium alcoholate & 7.16 & 7.375 & 1.0 \\
acetic acid & 39.38 & 37.50 & 26.0 \\
ethylene glycol & 6.22 & 5.60 & 4.0 \\
DI-water & 0.45 & 0.45 & 1.0 \\
\hline
\end{tabular}

After complete dissolution of all starting materials, the reaction was started by heating up to $150^{\circ} \mathrm{C}$ at a heating rate of $5 \mathrm{~K} \cdot \mathrm{min}^{-1}$ and held for $10 \mathrm{~h}$. The solution was then dried at $110^{\circ} \mathrm{C}$ for $24 \mathrm{~h}$ in an oven under an air flow of $51 \cdot \mathrm{min}^{-1}$.

\section{$\mathrm{BCB}\left(\mathrm{BaCuB}{ }_{2} \mathrm{O}_{5}\right)$}

The liquid phase sintering aid BCB was synthesized by mixing, drying, and calcination of the starting materials barium carbonate, copper oxide, and boric acid, using the process described by Jiang et al. [18]. Mixing was performed according to the BST powder. The precursor was dried using the same rotary evaporator as for BST powder. After drying, the precursor was calcined in a chamber furnace (CWF 1300, Carbolite) inside a crucible $\left(\mathrm{Al}_{2} \mathrm{O}_{3}\right)$ at $850^{\circ} \mathrm{C}$ for $3 \mathrm{~h}$ with a heating and cooling rate of $5 \mathrm{~K} \cdot \mathrm{min}^{-1}$ as well as an air flow of $51 \cdot \mathrm{min}^{-1}$. Subsequently the powder was ground by hand.

\section{Fabrication of pellets}

For dilatometric measurements, pellets with good homogeneity are required. To this end, BST powder, BST gel, and BCB were mixed in a planetary mill with 2-Propanol as a dispersing medium together with $\mathrm{ZrO}_{2}$ grinding balls. For better handling during the pressing process, 3 vol. \% of organic compounds were added consisting of a binder (polyvinylalcohol) and a pressing aid (glycerol). BST gel acts as a pressing aid, so glycerol was only necessary for the formation of pellets without BST gel. To prevent barium ions from dissolving, an aqueous solution of ammonium carbonate was added to all mixtures [34].

To obtain stable pellets with low defect concentrations and high densities, powder mixtures were presolidified by uniaxial pressure in a cylinder shaped extrusion die (diameter $20 \mathrm{~mm}$ ) using a hydraulic press (PW $20 \mathrm{HS}$, Weber). Here, stearic acid was used as a lubricant. After pre-solidification the powder was pound and finally pressed to pellets by uniaxial pressure in a cylinder shaped extrusion die (diameter $10 \mathrm{~mm}$ ). The pressing parameters are given in Table 3.

Table 3. Pressing parameters for pre-solidification and the final pellets.

\begin{tabular}{lcc}
\hline & Pre-solidification & Final pellets \\
\hline Extrusion die diameter $(\mathrm{mm})$ & 20 & 10 \\
Pressing force $(\mathrm{kN})$ & 150 & 12 \\
Pressure $(\mathrm{MPa})$ & 478 & 153 \\
Pressing time $(\mathrm{min})$ & 1 & 1 \\
\hline
\end{tabular}

BST gel was added to the pellets with different amounts ranging from 0 to 100 vol. $\%$, BCB was added with 1 and $2.5 \mathrm{~mol} \%$ with respect to the BST content. The compositions of all produced mixtures and pellets are listed in Table 4.

Table 4. Compositions consisting of BST gel, BCB and BCT powder of all investigated mixtures and pellets.

\begin{tabular}{ccc}
\hline $\begin{array}{c}\text { BST gel } \\
\text { (vol. \%) }\end{array}$ & $\begin{array}{c}\text { BCB } \\
(\text { mol. \%) }\end{array}$ & $\begin{array}{c}\text { BST powder } \\
\text { (vol. \%) }\end{array}$ \\
\hline 0 & 0 & 100 \\
0 & 1 & 100 \\
0 & 2.5 & 100 \\
10 & 0 & 90 \\
10 & 1 & 90 \\
10 & 2.5 & 90 \\
15 & 0 & 85 \\
35 & 0 & 65 \\
35 & 1 & 65 \\
35 & 2.5 & 65 \\
50 & 0 & 50 \\
73 & 0 & 27 \\
84 & 0 & 16 \\
100 & 0 & 0 \\
\hline
\end{tabular}

\section{Characterization (experimental setup)}

The crystalline phase composition of sintered pellets were determined by XRD using a diffractometer (D5000, Siemens) in the Bragg-Brentano geometry. 
The exposure wavelength of the monochromatic X-radiation was $\lambda=1.54 \AA(\mathrm{Cu} \mathrm{K} \alpha)$, the anglular range $20-60^{\circ}$ $[35,36]$. The particle size distribution of the BST powder was measured in 2-Propanol using a laser diffraction instrument (LS230, Beckman-Coulter), over a measuring range from $40 \mathrm{~nm}$ to $2 \mathrm{~mm}$. Specific surface area was measured using a surface area analyser (Gemini VII 2390, Micromeritics). The density of the produced powders was determined using a helium pycnometer (Pycnomatic ATC, Thermo Scientific). Thermogravimetric and differential thermal analysis (TG-DTA) was performed with $5 \mathrm{~K} \cdot \mathrm{min}^{-1}$ heating and cooling rates under an ambient air flow of $0.11 \cdot \mathrm{min}^{-1}$ (STA 409 Jupiter, Netzsch). Dilatometric examination was carried out (Dil 402C, Netzsch) at an air flow of $0.11 \cdot \mathrm{min}^{-1}$ and heating and cooling rates of $5 \mathrm{~K} \cdot \mathrm{min}^{-1}$. Pellet density was analyzed using the Archimedean principle [37, 38]. SEM images were taken (DSM 962, Zeiss) and the quality factor (Q) of the pellets was measured at $1 \mathrm{kHz}$ and room temperature using a precision LCR meter (LCR-800, GW Instek).

\section{RESULTS AND DISCUSSION}

\section{Materials \\ BST powder}

The density and specific surface of the BST powder before and after grinding as well as after sintering are shown in Table 5. After grinding, the particle size is smaller and therefore the specific surface area of the

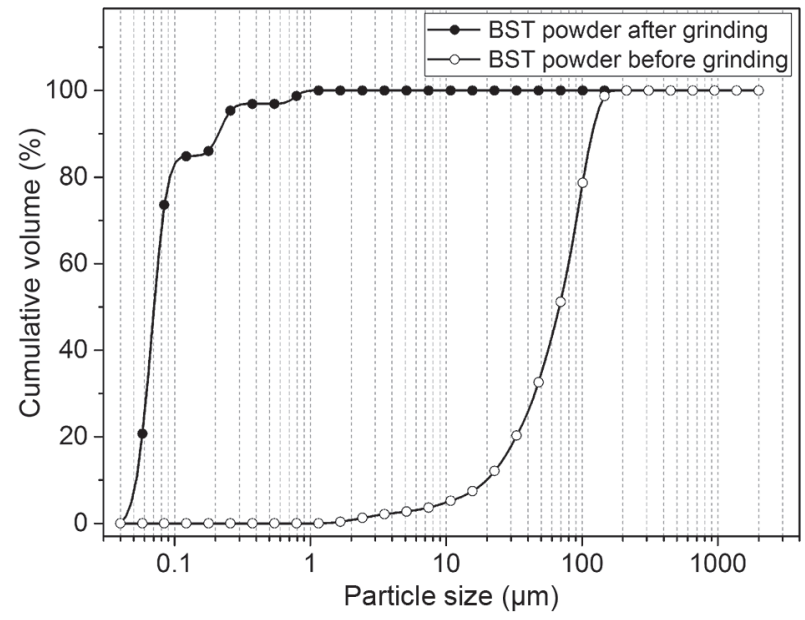

Figure 2. Particle size distribution of calcined BST powder before and after grinding. powder is increased by a factor of approximately three. Sintering causes density to increase to $5.69 \mathrm{~g} \cdot \mathrm{cm}^{-3}$, which is close to the theoretical value of $5.683 \mathrm{~g} \cdot \mathrm{cm}^{-3}$ found in literature [13]. The $\mathrm{D}_{50}$ and $\mathrm{D}_{90}$ are given in Table 5 and the particle size distributions of the calcined powders before and after grinding are shown in Figure 2 .

\section{BST gel}

The sintered density and specific surface of the BST gel were measured after synthesis, pyrolysis, and sintering. The results are listed in Table 6. Compared to the BST powder, the specific surface area of the synthesized BST gel was more than 10 times larger, which results in high activity during sintering. After sintering, the specific surface area was found to be lower compared to BST powder, which confirmed the high sintering activity.

Table 6. Density and specific surface area of BST gel after synthesis, pyrolysis, and sintering.

\begin{tabular}{lcc}
\hline BST gel & $\begin{array}{c}\text { Density } \\
\left(\mathrm{g} \cdot \mathrm{cm}^{-3}\right)\end{array}$ & $\begin{array}{c}\text { Specific surface } \\
\text { area }\left(\mathrm{m}^{2} \cdot \mathrm{g}^{-1}\right)\end{array}$ \\
\hline after synthesis & 2.32 & 196.1 \\
after pyrolysis $\left(450^{\circ} \mathrm{C}, 1 \mathrm{~h}\right)$ & 4.20 & 49.7 \\
after sintering $\left(1200^{\circ} \mathrm{C}, 1 \mathrm{~h}\right)$ & 5.61 & 0.78 \\
\hline
\end{tabular}

Figure 3 shows a TG-DTA measurement of the BST gel. The thermal voltage shows an exothermal peak at a temperature of about $400^{\circ} \mathrm{C}$. At this temperature the organic compounds are combusted. Carbonaceous spe-

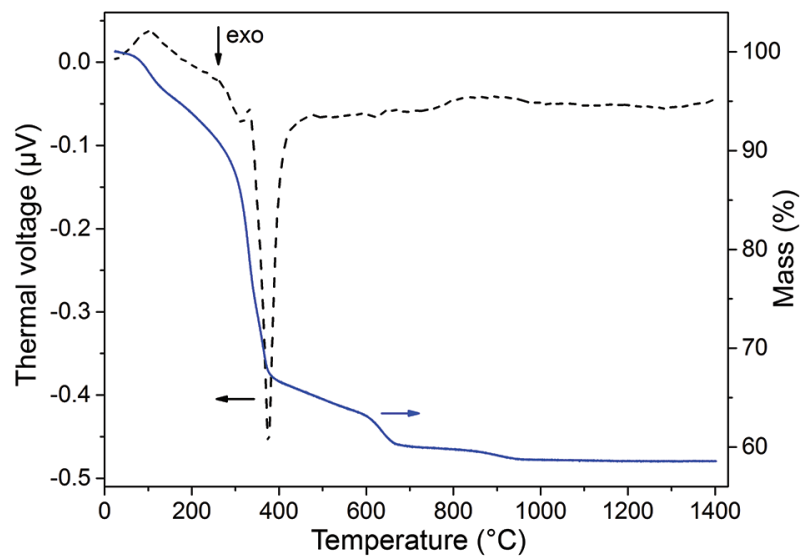

Figure 3. Combined TG-DTA measurement of BST gel under ambient conditions and a temperature up to $1400^{\circ} \mathrm{C}$.

Table 5. Density, specific surface, $\mathrm{D}_{50}$, and $\mathrm{D}_{90}$ values of synthesized BST powder before and after grinding as well as after sintering.

\begin{tabular}{lcccc}
\hline BST powder & Density $\left(\mathrm{g} \cdot \mathrm{cm}^{-3}\right)$ & Specific surface area $\left(\mathrm{m}^{2} \cdot \mathrm{g}^{-1}\right)$ & $\mathrm{D}_{50}(\mu \mathrm{m})$ & $\mathrm{D}_{90}(\mu \mathrm{m})$ \\
\hline Calcined, before grinding & 5.50 & 5.6 & 68 & 118 \\
Calcined, after grinding & & 17.3 & 0.07 & 0.2 \\
After sintering $\left(1200^{\circ} \mathrm{C}, 1 \mathrm{~h}\right)$ & 5.69 & 2.8 & - & \\
\hline
\end{tabular}


cies are formed during combustion, which decompose in a two-stage reaction up to $950^{\circ} \mathrm{C}[13]$. At this temperature, the mass loss is about $32 \%$ and increases to more than $40 \%$ for $1400^{\circ} \mathrm{C}$. The total volume shrinkage of about $80 \%$, which can be calculated from the mass loss and density, is due to ethylene glycol. After sintering, XRD was carried out (Figure 4), which indicates a slightly higher amount of strontium [25].

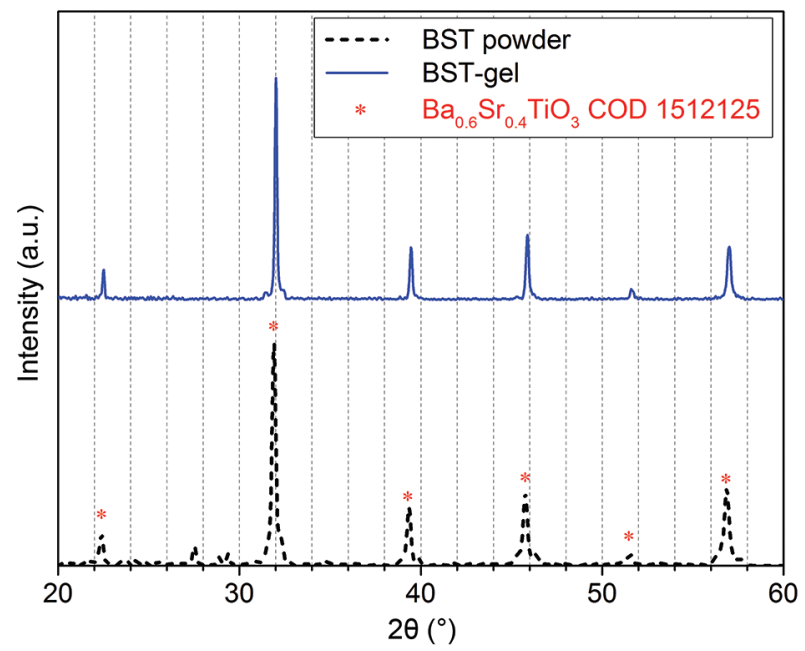

Figure 4. XRD measurement results for BST powder and BST gel and reference out of Crystallography Open Database (COD).

\section{$B C B$}

The synthesized BCB was verified using XRD (Figure 5), and was found to match database values very well. Figure 6 shows TG-DTA measurements of calcined $\mathrm{BCB}$ with no mass loss up to $900^{\circ} \mathrm{C}$. The melting point is about $890^{\circ} \mathrm{C}$, which is lower than the value $930^{\circ} \mathrm{C}$ reported by Kim et al. [17].

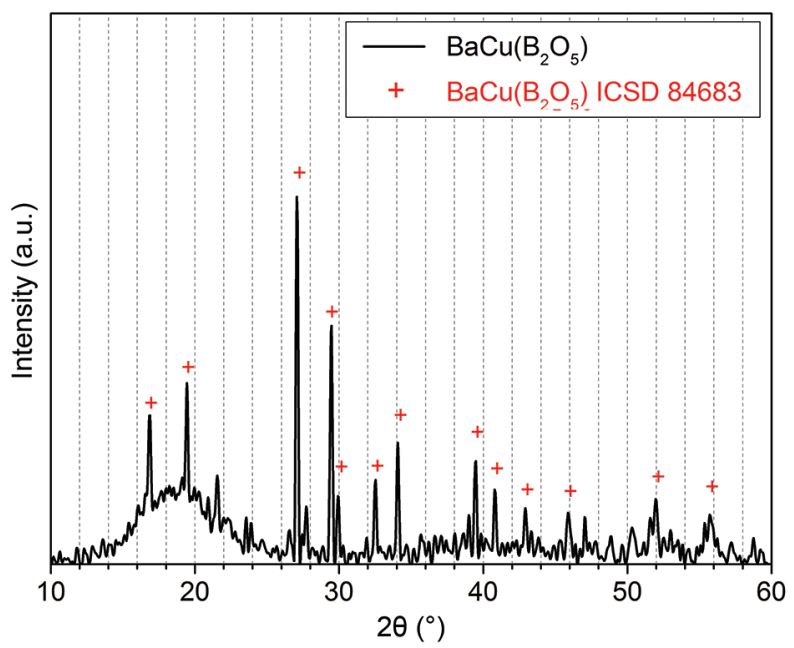

Figure 5. XRD measurement result for $\mathrm{BaCuB}_{2} \mathrm{O}_{5}(\mathrm{BCB})$ powder and reference out of Inorganic Crystal Structure Database (ICSD).

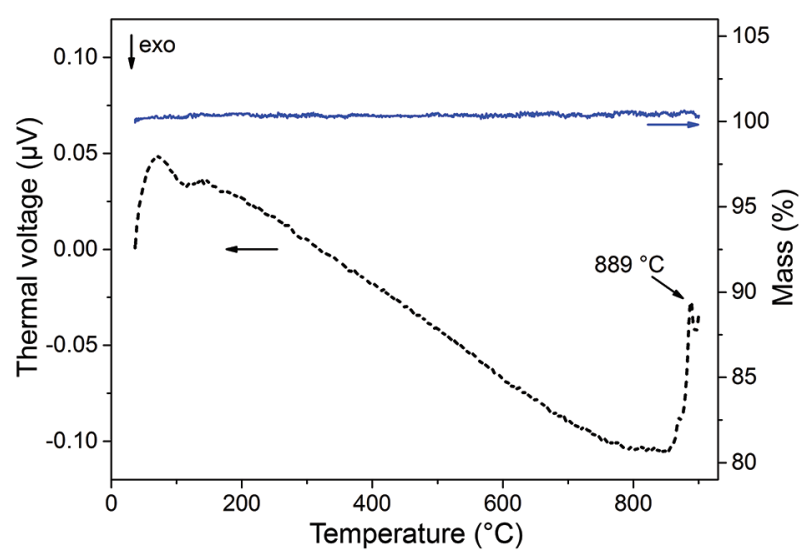

Figure 6. Combined TG-DTA measurement of calcined BCB under ambient conditions for a temperature up to $900^{\circ} \mathrm{C}$.

Shrinkage behaviour

BST gel as a sintering aid

Figure 7 compares the temperature dependent shrinkage of different BST powder/BST gel compositions, and shows the suitability of BST gel as a sintering aid. The total shrinkage can be divided into three parts. In part I of Figure $7\left(\mathrm{~T}<700^{\circ} \mathrm{C}\right)$, the shrinkage is directly related to the mass loss. In the second part $\left(987^{\circ} \mathrm{C}<\mathrm{T}<1161^{\circ} \mathrm{C}\right)$ shrinkage is caused by the onset of sintering, mainly as a function of the BST gel content and marked by the grey area. The onset temperatures (Table 7), which indicate the start of sintering, were determined with Proteus Analysis Software (Netzsch) using the tangent method. A higher BST gel concentration results clearly in lower onset temperatures but also in slower shrinkage at higher temperatures. Slower shrinkage is mostly caused by increased porosity and therefore smaller contact surface between the individual ceramic particles. In the third part, sintering slows down for pellets with more than 35 vol. \% BST-gel, probably because the high surface area is mainly "consumed" and therefore the driving force of the sintering process is gone.

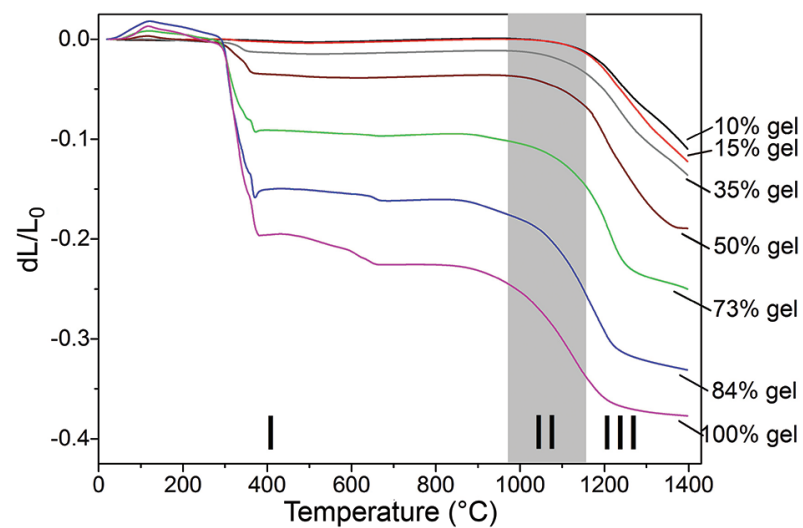

Figure 7. Dilatometric measurements of the linear shrinkage of different BST powder/BST gel mixtures depending on the temperature. 
Table 7. Onset temperatures for the different pellets with BST gel, determined with Proteus Analysis Software (Netzsch) using the tangent method.

\begin{tabular}{cc}
\hline $\begin{array}{c}\text { BST-gel content } \\
\text { (vol. \%) }\end{array}$ & $\begin{array}{c}\text { Tonset } \\
\left({ }^{\circ} \mathrm{C}\right)\end{array}$ \\
\hline 0 & 1161 \\
10 & 1143 \\
15 & 1137 \\
35 & 1130 \\
50 & 1120 \\
73 & 1119 \\
84 & 1043 \\
100 & 987 \\
\hline
\end{tabular}

\section{$B C B$ as a sintering aid}

In Figure 8 , the temperature-dependent linear shrinkage for mixtures with 0,1 and 2.5 mol. \% BCB is shown. The sintering behaviour up to $750^{\circ} \mathrm{C}$ is similar to the mixtures without $\mathrm{BCB}$. The onset temperatures (Table 8) hold an inverse relationship with $\mathrm{BCB}$ concentration, decreasing from $880^{\circ} \mathrm{C}$ for $1 \mathrm{~mol} . \%$ to $849^{\circ} \mathrm{C}$ for $2.5 \mathrm{~mol} . \%$. Compared to pellets without $\mathrm{BCB}$ these onset temperatures are up to $312^{\circ} \mathrm{C}$ lower. Moreover, shrinkage slope is greater compared to pellets without BCB. Both facts lead to huge advantages realizing maximum densities at low temperatures.

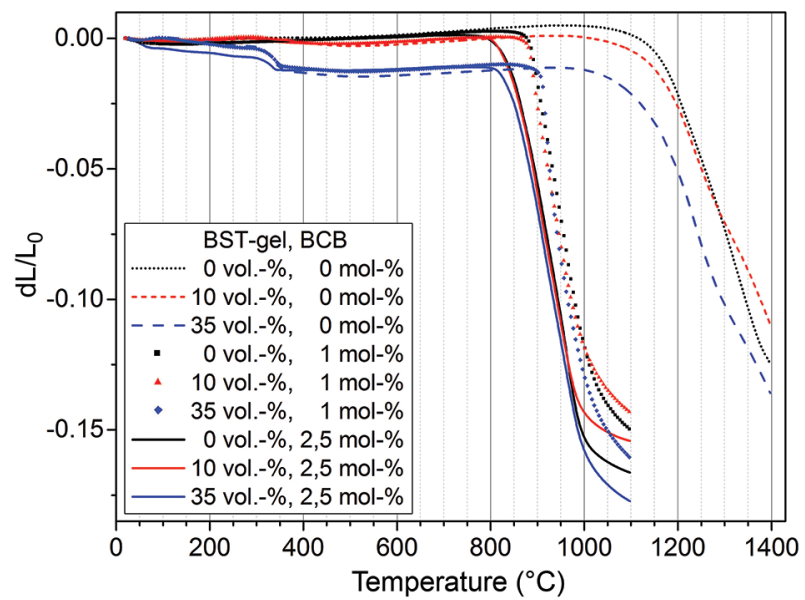

Figure 8. Dilatometric measurements of pellets out of different BST gel and BCB mixtures.

Adding 35 vol. \% BST-gel to the mixture with $1 \mathrm{~mol}$. \% BCB the onset temperature was increased to $908^{\circ} \mathrm{C}$. BST-gel did not influence mixtures with $2.5 \mathrm{~mol} . \%$ $\mathrm{BCB}$ concerning onset temperature. TG-DTA-analysis of the BCB mixtures showed that the shrinkage is only caused by sintering and not due to decomposition of $\mathrm{BCB}$ (compare Figure 6).
Table 8. Onset temperatures for the different pellets with BST gel, determined with Proteus Analysis Software (Netzsch) using the tangent method.

\begin{tabular}{ccc}
\hline $\begin{array}{c}\text { BST-gel content } \\
\text { (vol. \%) }\end{array}$ & $\begin{array}{c}\text { BCB content } \\
(\text { mol. \%) }\end{array}$ & $\begin{array}{c}\mathrm{T}_{\text {onset }} \\
\left({ }^{\circ} \mathrm{C}\right)\end{array}$ \\
\hline 0 & 1 & 880 \\
10 & 1 & 879 \\
35 & 1 & 908 \\
0 & 2.5 & 849 \\
10 & 2.5 & 840 \\
35 & 2.5 & 845 \\
\hline
\end{tabular}

Density

BST gel as sintering aid

Figure 9 shows relative sinter densities with respect to the theoretical value of BST60 [13], as well as the absolute densities for sintering temperatures up to $1400^{\circ} \mathrm{C}$ for different contents of BST gel. The sintered density of the pellets depends on the shrinkage during heating and the densification during dwelling time $(5 \mathrm{~h})$.

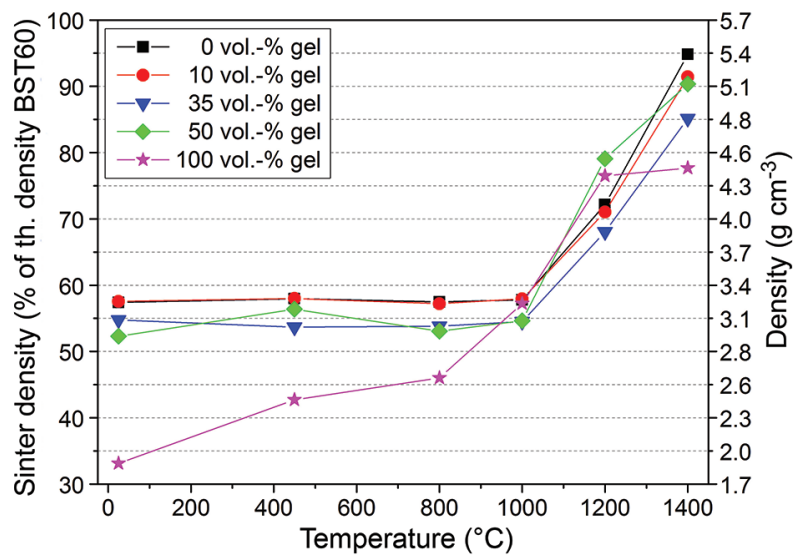

Figure 9. Relative and absolute sinter densities of pellets containing BST-powder and BST-gel, which are sintered at temperatures up to $1400^{\circ} \mathrm{C}$ for $5 \mathrm{~h}$.

As previously mentioned, BST gel has a very high mass loss below $700^{\circ} \mathrm{C}$, resulting in increased porosity. However, simultaneous shrinkage during this phase causes the density to remain constant. Between $1000^{\circ} \mathrm{C}$ and $1200^{\circ} \mathrm{C}$, sinter activity increases greatly (compare onset temperatures - Table 7), resulting in increased density. At $1200^{\circ} \mathrm{C}$ the high specific surface area of the BST gel is mainly expended and remains constant. Therefore hardly further sintering (compare Figure 7) and accordingly only a slight increase in density is observed. For a sintering temperature of $1400^{\circ} \mathrm{C}$ the sintered density increases with decreasing BST gel content and shows a maximum for 0 vol. \%. 
Figure 10 shows the relationship between sintered density and sintering temperature for various amounts of BST gel and two different contents of BCB. The required sintering temperatures are lower due to the use of BCB. At these reduced sintering temperatures, the activation of the high sinter active surface of the BST gel is hampered and therefore no positive effect on the sintering can be seen. For a given temperature, the density increases for a higher content of BCB and lower content of BST gel. For a temperature rise from $875^{\circ} \mathrm{C}$ to $950^{\circ} \mathrm{C}$ ) the relative density increases from 65 to $82 \%$ for 35 vol. \% BST gel and 1 mol. \% BCB. By increasing the BCB content to 2.5 mol. \% the relative density increases by another $10 \%$. This behavior is caused by the higher amount of liquid phase (BCB), which leads to faster sintering. Table 9 gives an overview of selected density values of pellets with different $\mathrm{BST}$, BST gel and $\mathrm{BCB}$ concentrations sintered at $950^{\circ} \mathrm{C}\left(1000^{\circ} \mathrm{C}\right), 1200^{\circ} \mathrm{C}$ and $1400^{\circ} \mathrm{C}$.

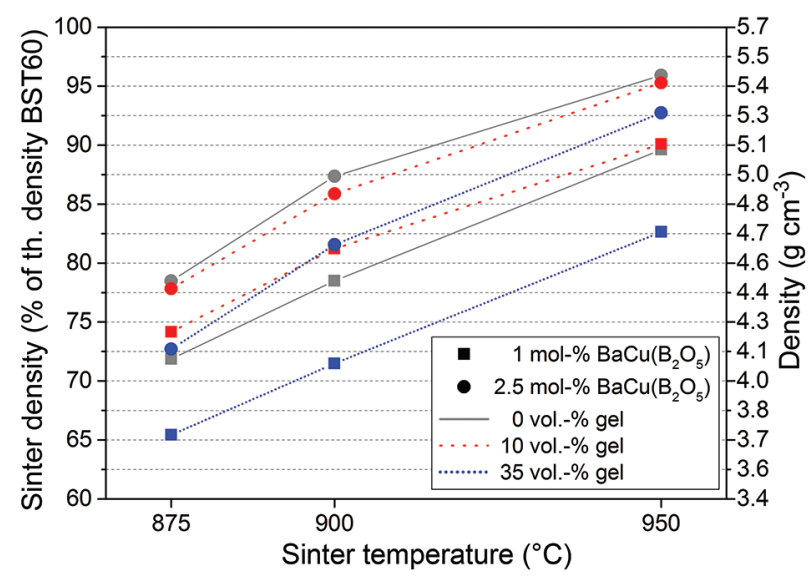

Figure 10. Sinter densities of pellets out of BST powder, BST gel and $\mathrm{BCB}$ at different sintering temperatures.

\section{Morphology}

SEM pictures were taken to investigate the material structure and grain size of the sintered pellets. In Figure 11 (upper row) pellets with 0 and 35 vol. \% BST gel sintered at $1200^{\circ} \mathrm{C}$ are compared. Both pellets show dense areas, whereas porosity is higher for the pellets containing BST gel. This can also be seen in the density measurements, where the pellet without BST gel shows a higher density at this temperature. In addition, material fragments were pulled out of the bulk due to mechanical erosion during polishing.

SEM pictures of pellets sintered at $1400^{\circ} \mathrm{C}$ for $5 \mathrm{~h}$ illustrate the influence of BST gel on the sintered density. In Figure 11 (lower row) pellets with 0 and 10 vol. \% BST gel are shown. 10 vol. \% were chosen, because the sample with 35 vol. \% BST gel showed no visible grains and also mechanical erosion from polishing. Samples with 0 vol. \% BST gel indicate a higher density, even when compared to samples with 10 vol.\%, which was also confirmed by measuring the density with the Archimedean principle. They also show closer but bigger grains and less porosity.

SEM pictures of pellets out of pure BST gel sintered at 450,1200 , and $1400^{\circ} \mathrm{C}$ (top) as well as pellets with BST gel contents of 0,10 , and 35 vol. \% with $2.5 \mathrm{~mol} . \%$ BCB (bottom) are illustrated in Figure 12. Figure 12a shows a pellet sintered at $450^{\circ} \mathrm{C}$ for $1 \mathrm{~h}$. At this temperature most organic compounds are decomposed. The surface indicates areas of high density but also large breaks and areas of high porosity. Figure $12 \mathrm{~b}$ and $\mathrm{c}$ show samples sintered at $1200^{\circ} \mathrm{C}$ and $1400^{\circ} \mathrm{C}$, respectively. No big difference can be seen as there are dense areas as well as porosity. This result can also be found in Figure 9, where only a small increase in density is shown.

Figure 12 (lower row) shows SEM pictures of pellets with 2.5 mol. \% BCB and 0, 10, and 35 vol. \% BST gel. The difference between these samples with respect to grain size, density, and porosity is negligible. The reason for this is the low sintering temperature, at which the BST gel is not yet activated. Only the BCB influences the sintering behavior and therefore grain size and density.

\section{Summary of microstructural characteristics}

The sintered density of pellets with 50, 73 and 84 vol. $\%$ BST gel sintered at $1200^{\circ} \mathrm{C}$ is higher compared to pellets made from BST powder with a content of BST gel lower than 35 vol. \%. At higher temperatures the BST gel showed no advantages with respect to the sintered density. By adding BST gel to the BST powder the onset

Table 9. Overview of selected density values of pellets with different amounts of BST gel and BCB sintered at temperatures in the range of 950 to $1400^{\circ} \mathrm{C}$.

\begin{tabular}{|c|c|c|c|c|}
\hline \multirow{2}{*}{ BST gel content (vol.\%) } & \multirow{2}{*}{ BCB content (mol.\%) } & \multicolumn{3}{|c|}{ Density ( $\%$ of theoretical density) } \\
\hline & & $950^{\circ} \mathrm{C}\left(1000^{\circ} \mathrm{C}\right)$ & $1200^{\circ} \mathrm{C}$ & $1400^{\circ} \mathrm{C}$ \\
\hline 0 & 0 & $(58)$ & 72 & 95 \\
\hline 50 & 0 & $(55)$ & 79 & 90 \\
\hline 100 & 0 & (57) & 77 & 78 \\
\hline 0 & 2.5 & 96 & - & - \\
\hline 10 & 2.5 & 95 & - & - \\
\hline 35 & 2.5 & 93 & - & - \\
\hline
\end{tabular}

Ceramics - Silikáty 60 (1) 1-11 (2016) 
temperature decreased with increasing content but the maximum density reached is lower.

Mixtures with $\mathrm{BCB}$ as liquid phase sintering aid achieved high densities at low sintering temperatures. Due to the low sintering temperatures which are below

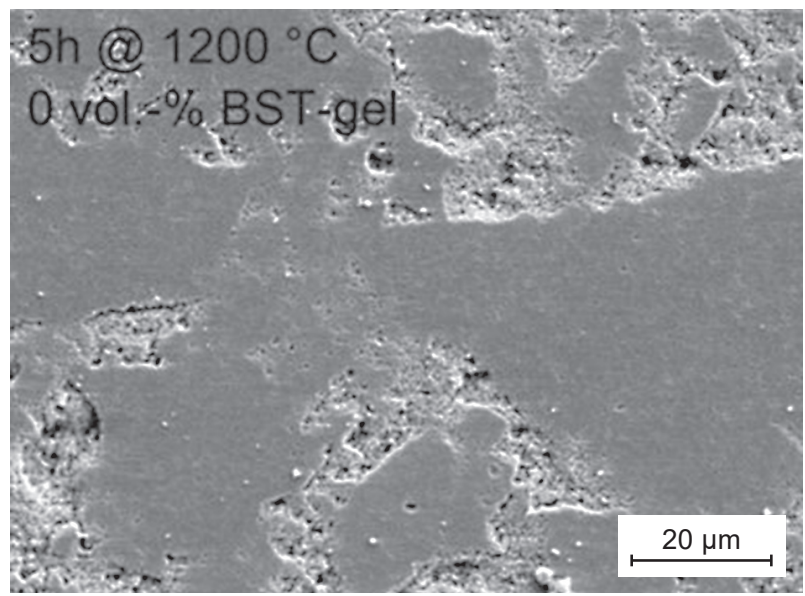

a)

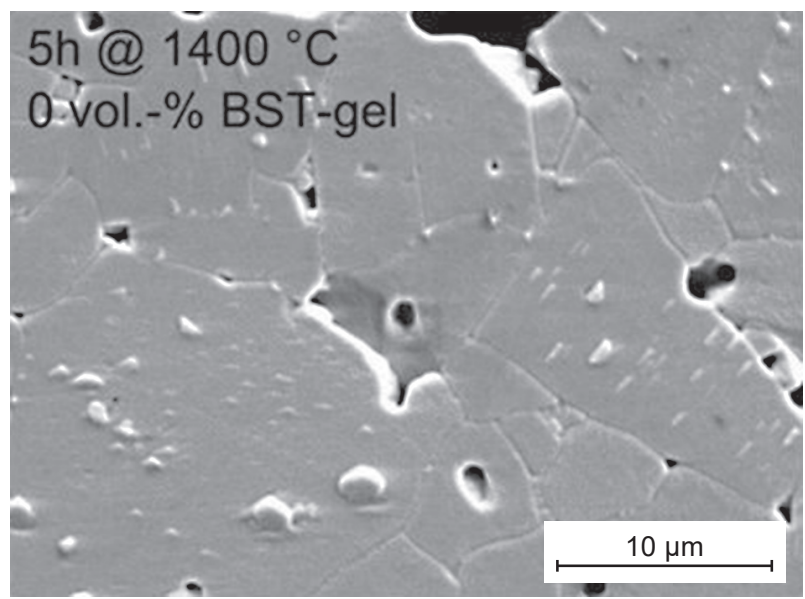

c) the activation temperature of the BST gel, the addition of BST gel to the mixtures with BCB showed no improvements with respect to final density and onset temperatures.

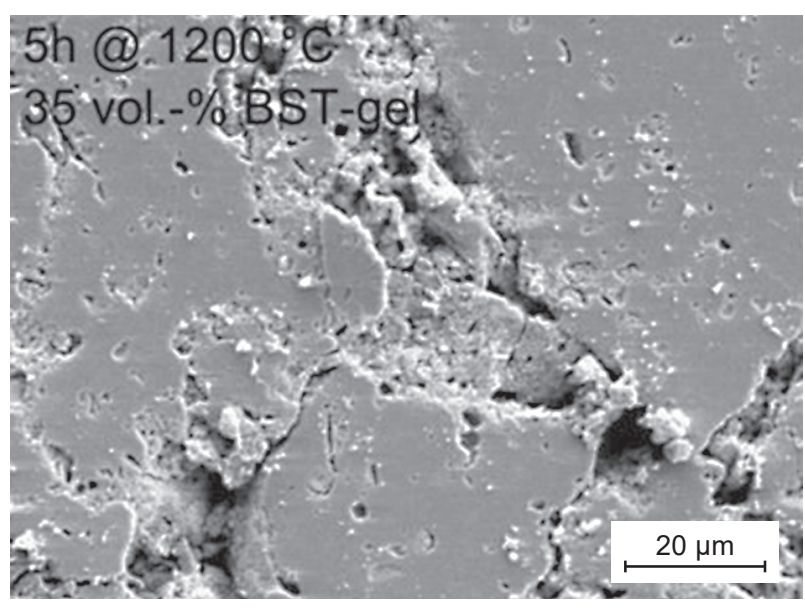

b)

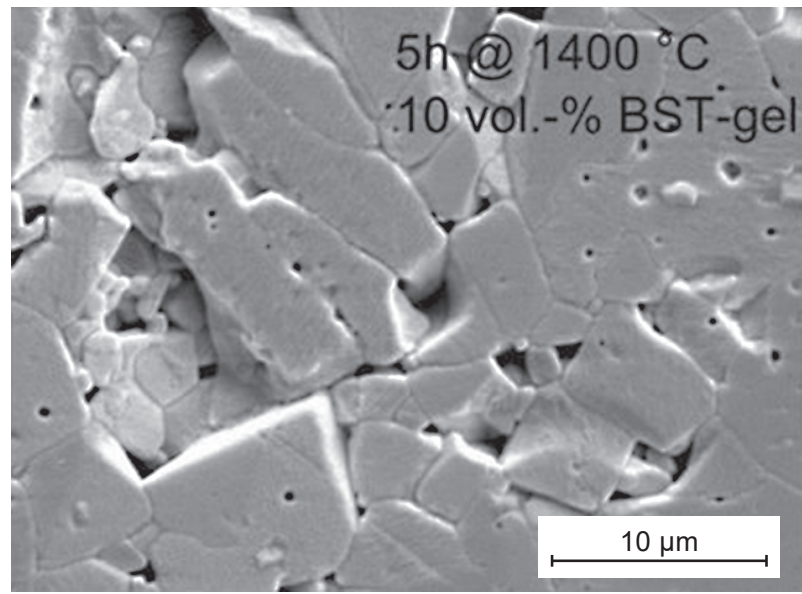

d)

Figure 11. SEM pictures of pellets out of BST powder (a, c) and out of BST powder and 35 vol. \% (b) and 10 vol. \% BST gel (c) sintered at 1200 (top) and $1400^{\circ} \mathrm{C}$ (bottom).

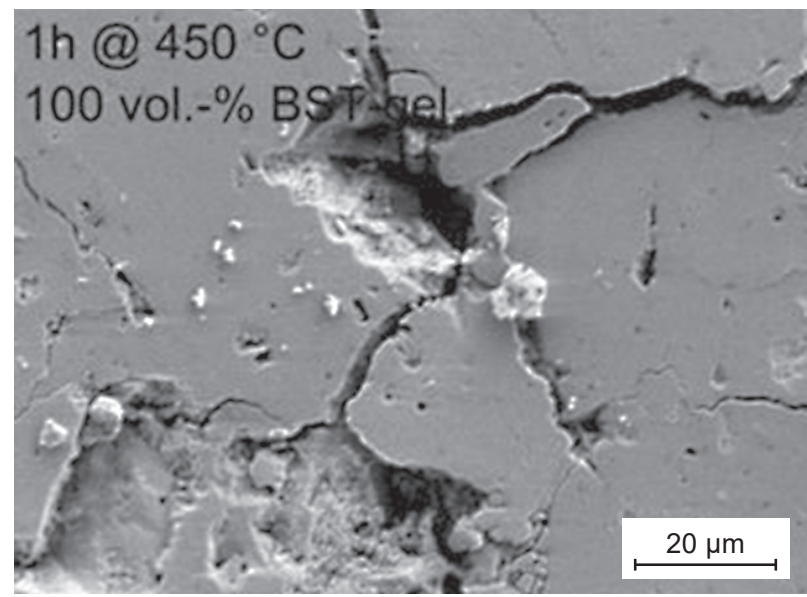

a)

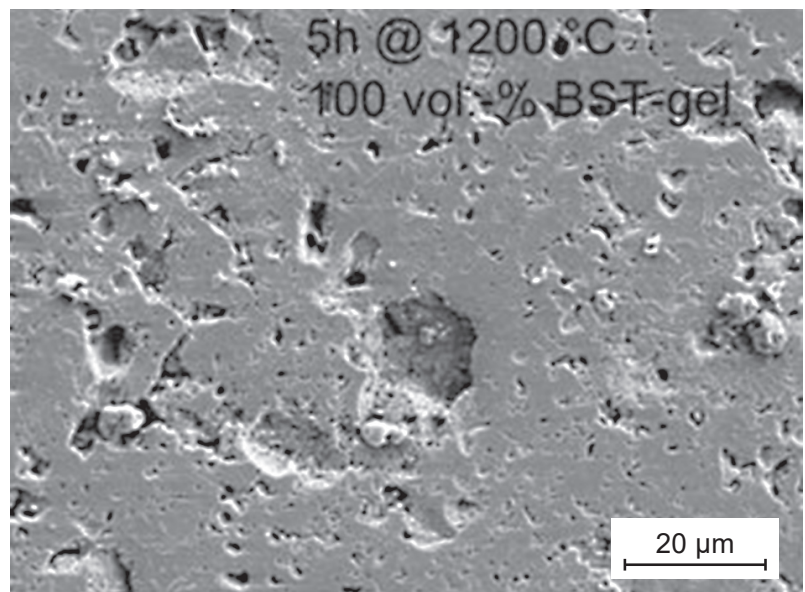

b)

Figure 12. SEM pictures of pellets out of BST gel (top) sintered at $450^{\circ} \mathrm{C}(\mathrm{a}), 1200^{\circ} \mathrm{C}$ (b) and $1400^{\circ} \mathrm{C}$ (c) and pellets out of BST powder, BCB (bottom) and 0 vol. \% (d), 10 vol. \% (e) and 35 vol. \% (f) BST gel sintered at $950^{\circ} \mathrm{C}$ and 5 h. Continue on next page 


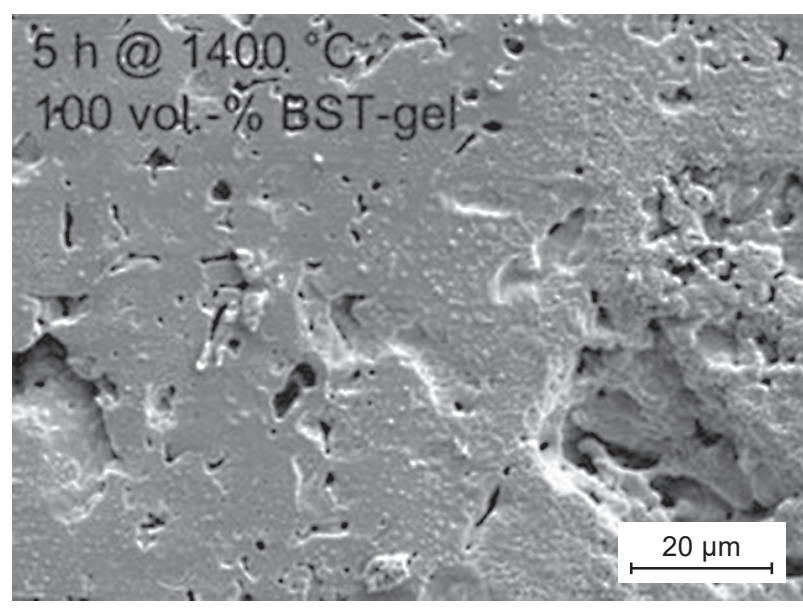

c)

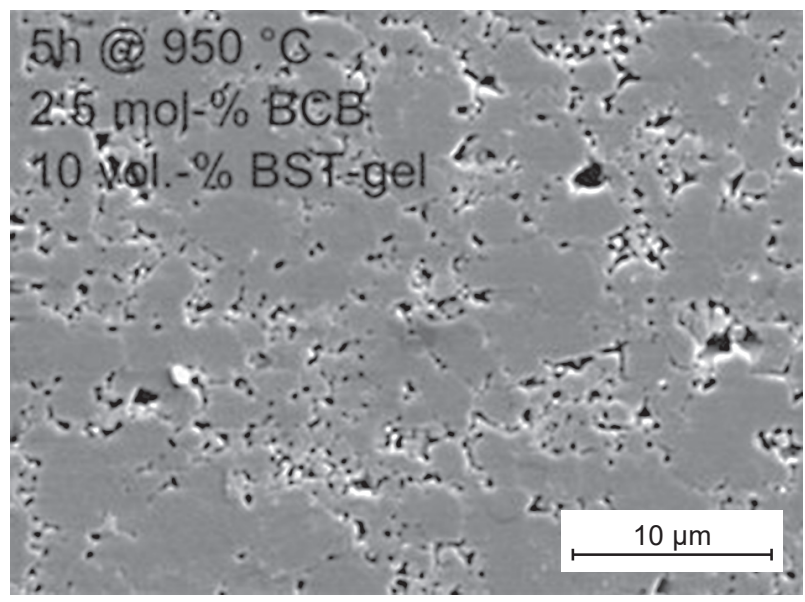

e)

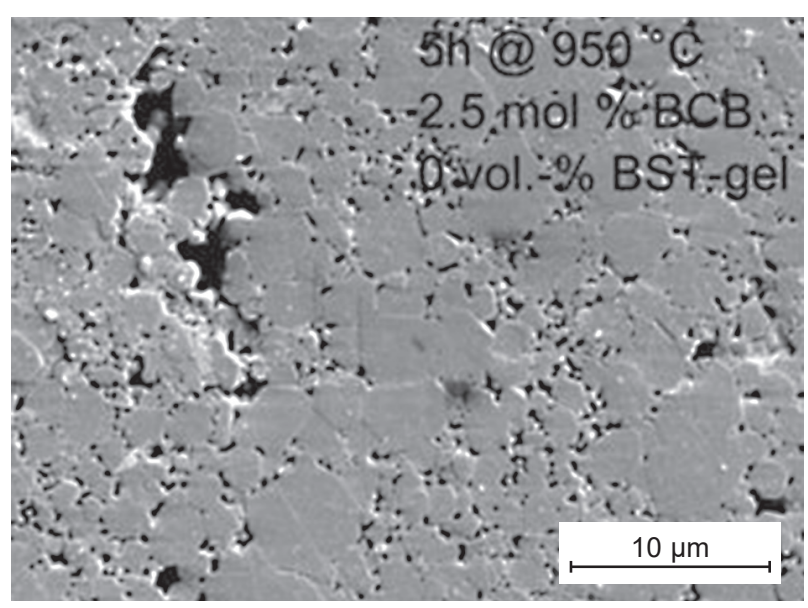

d)

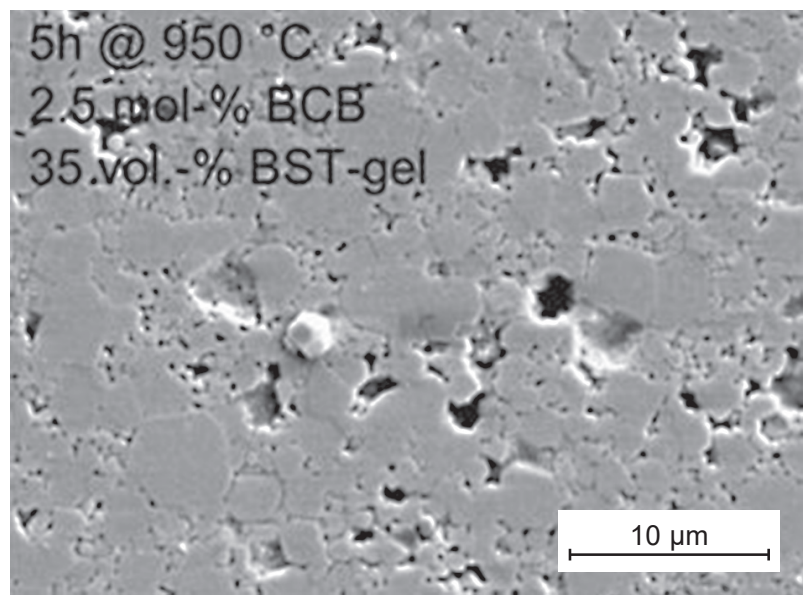

f)

Figure 11. SEM pictures of pellets out of BST powder (a, c) and out of BST powder and 35 vol. \% (b) and 10 vol. \% BST gel (c) sintered at 1200 (top) and $1400^{\circ} \mathrm{C}$ (bottom).

\section{Dielectric measurements}

Figure 13 shows the influence of different amounts of BST gel and BCB on the quality factor. The quality factor was measured at $1 \mathrm{kHz}$ using a LCR meter. The

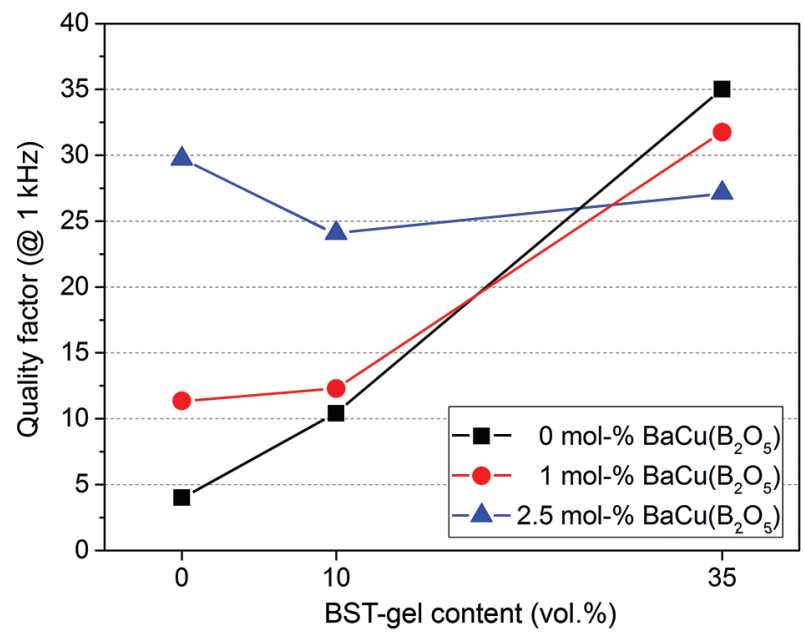

Figure 13. Dielectric measurements of quality factor @ 1 kHz using a LCR meter depending of BCB and BST gel content. quality factor increases for lower porosity. This behavior can be seen for samples with increasing content of BST gel with 0 and 1 mol. \% BCB. For samples with 2.5 mol. \% BCB, the Q-factor shows a minimum for 10 vol. \%. These results need further investigation at thick films.

\section{CONCLUSION}

In this paper, BST and BCB powders were synthesized using the mixed oxide route, as well as BST gel using a sol-gel process. For the usage of BST gel as a sintering aid, its concentration must be above a threshold of 35 vol. $\%$ for it to influence the final density. The onset temperature was seen to decrease by up to $174^{\circ} \mathrm{C}$ for pure BST gel. For a sintering temperature of around $1200^{\circ} \mathrm{C}$ and dwelling times of $5 \mathrm{~h}$, the densities of pellets with BST gel are significantly higher compared to the samples without BST gel. At a sintering temperature of $1400^{\circ} \mathrm{C}$, these samples could not reach the final density of pure BST powder.

Pellets with $\mathrm{BCB}$ reached its maximum density at a sintering temperature of $950^{\circ} \mathrm{C}$ over a dwelling

Ceramics - Silikáty 60 (1) 1-11 (2016) 
time of $5 \mathrm{~h}$. The onset temperature decreased with increasing content of $\mathrm{BCB}$ as a liquid phase sintering aid. For $1 \mathrm{~mol}$. \% $\mathrm{BCB}$ it was possible to reduce the onset temperature by $281^{\circ} \mathrm{C}$ and with $2.5 \mathrm{~mol}$. \% even by $312^{\circ} \mathrm{C}$. Overall, sintering occurred much faster when compared to pure BST and therefore much lower temperatures were needed to reach the highest density of $5.41 \mathrm{~g} \cdot \mathrm{cm}^{-3}(96 \%)$. This is very promising compared to other liquid sintering aids like $\mathrm{B}_{2} \mathrm{O}_{3}-\mathrm{Li}_{2} \mathrm{CO}_{3}$ which only reached $5.22 \mathrm{~g} \cdot \mathrm{cm}^{-3}$ [20]. Additional BST gel did not reduce the onset temperature or the maximum density any further.

During fabrication of the pellets, the BST gel exhibited a binding effect on the pellets. This could be particularly useful in other fabrication technologies like electrophoretic deposition (EPD), which is used for realization of thick films [39, 40].

Dielectric measurements verified that the quality factor increased with an increasing content of BST gel. Further analysis of the dielectric measurement such as relative dielectric constant and loss tangent vs. temperature at different frequencies is very challenging with bulk ceramics due to the high voltages required. Therefore thick films have to be produced and investigated in the future.

Further progress should also concentrate on a higher ceramic yield of BST gel to prevent high porosity due to organic decomposition. Another possibility could be the pyrolysis of $\mathrm{BST}$ gel at $450^{\circ} \mathrm{C}$ and adding it in different amounts to the mixtures. For this, the described fabrication process of this investigation could be used. The other benefit would be that most of the organic compounds of the BST gel are already decomposed while the specific surface area is still high. This should still lead to a high sinter activity which results then again in high densities.

\section{Acknowledgments}

The authors thank Ms. Offermann from Karlsruhe Institute of Technology (KIT, Germany) for measuring powder densities and specific surfaces. The authors also acknowledge financial support by Deutsche Forschungsgesellschaft (DFG).

\section{REFERENCES}

1. Haertling G.H. (1999): Ferroelectric ceramics: History and technology. Journal of the American ceramic society, 82(4), 797-818. doi:10.1111/j.1151-2916.1999.tb01840.x.

2. Woong K., Shima H., Yamamoto T., Yasui S., Funakubo H., Yamada T., Nishida K. (2014): Preparation and characterization of $\mathrm{ba}\left(\mathrm{zr}_{x} \mathrm{ti} \mathrm{i}_{1-x}\right) \mathrm{O}_{3}$ thin films for highfrequency applications. Japanese Journal of Applied Physics, 53(9S), doi:09PB04. 10.1143/JJAP.51.09LA01.

3. Tagantsev A.K., Sherman V.O., Astafiev K.F., Venkatesh J., Setter N. (2003): Ferroelectric materials for microwave tunable applications. Journal of Electroceramics, 11(1-2), 5-66. doi:10.1023/B:JECR.0000015661.81386.e6.

4. Kwon S., Hackenberger W., Alberta E., Furman E., Lanagan M. (2011): Nonlinear dielectric ceramics and their applications to capacitors and tunable dielectrics. Electrical Insulation Magazine, IEEE, 27(2), 43-55. doi:10.1109/ MEI.2011.5739422.

5. Zhou X. (2012). Prozess- und Dotierungseinflüsse auf $\mathrm{Ba}_{0,6} \mathrm{Sr}_{0,4} \mathrm{TiO}_{3}$-Dickschichten für steuerbare Mikrowellenkomponenten. Dissertation. Technische Universität Darmstadt, Germany.

6. Babbitt R., Koscica T., Drach W., Didomenico L. (1995): Ferroelectric phase shifters and their performance in microwave phased array antennas. Integrated Ferroelectrics, 8(1-2), 65-76. doi:10.1080/10584589508012301.

7. Zimmermann F., Voigts M., Menesklou W., Ivers-Tiffée E. (2004): $\mathrm{Ba}_{0.6} \mathrm{Sr}_{0.4} \mathrm{TiO}_{3}$ and $\mathrm{BaZr}_{0.3} \mathrm{Ti}_{0.7} \mathrm{O}_{3}$ thick films as tunable microwave dielectrics. Journal of the European Ceramic Society, 24, 1729-1733. doi:10.1016/S09552219(03)00481-3.

8. Yamada T., Muralt P., Sherman V.O., Sandu C.S., Setter N. (2007) Epitaxial growth of $\mathrm{BaO} \cdot 3 \mathrm{Sr}_{0.7} \mathrm{TiO}_{3}$ thin films on $\mathrm{Al}_{2} \mathrm{O}_{3}(0001)$ using ultrathin tin layer as a sacrificial template. Applied Physics Letters, 90(14), 142911. doi:10.1063/1.2719673.

9. Zhang D., Hu W., Meggs C., Su B., Price T., Iddles D., Lancaster M.J., Button T.W. (2007): Fabrication and characterization of barium strontium titanate thick film device structures for microwave applications. Journal of the European Ceramic Society, 27(27), 1047-1051. doi:10.1016/j.jeurceramsoc.2006.05.051.

10.Oh S.-W., Park J.-H., Akedo J. (2007). Dielectric characterization of barium strontium titanate (bst) films prepared on cu substrate by aerosol deposited method, in Sixteenth IEEE International Symposium on Applications of Ferroelectrics. ISAF. pp. 207-208.

11.Jeon J.-H. (2004): Effect of $\mathrm{SrTiO}_{3}$ concentration and sintering temperature on microstructure and dielectric constant of $\mathrm{Ba}_{1-x} \mathrm{Sr}_{x} \mathrm{TiO}_{3}$. Journal of the European Ceramic Society, 24(6), 1045-1048. doi:10.1016/S09552219(03)00385-6.

12.Zimmermann F., Voigts M., Weil C., Jakoby R., Wang P., Menesklou W., Ivers-Tiffee E. (2001): Investigation of barium strontium titanate thick films for tunable phase shifters. Journal of the European Ceramic Society, 21 (10-11), 2019-2023. doi:10.1016/S0955-2219(01)00164-9.

13.Paul F. (2006). Dotierte $\mathrm{Ba}_{0,6} \mathrm{Sr}_{0,4} \mathrm{TiO}_{3}$-Dickschichten als steuerbare Dielektrika. PhD thesis. University of Freiburg, Germany.

14. Su B., Button T. (2001): The processing and properties of barium strontium titanate thick films for use in frequency agile microwave circuit applications. Journal of the European Ceramic Society, 21(15), 2641-2645. doi:10.1016/S0955-2219(01)00330-2.

15.Kim S., Koh J.-H. (2009) Dielectric Properties of ZnBO doped $(\mathrm{Ba}, \mathrm{Sr}) \mathrm{TiO}_{3}$ Ceramics for the low temperature sintering process. Integrated Ferroelectrics, 110(1), 17-24. doi:10.1080/10584580903435273.

16.Jiang H., Zhai J., Zhang J., Yao X. (2009): Dielectric Properties of Low-Temperature Sintered $\mathrm{BaO}_{6 .} \mathrm{Sr}_{\mathrm{O} .4} \mathrm{TiO}_{3}$ Ceramics by Addition of $\mathrm{Bi}_{2} \mathrm{O}_{3}-\mathrm{CuO}$ Mixed Oxides. Key Engineering Materials, 421-422, 61-64. doi:10.4028/ www.scientific.net/KEM.421-422.61. 
17.Kim M., Lim J., Kim J.-C., Nahm S., Paik J.-H., Kim J.-H., Park K.-S. (2006): Synthesis of $\mathrm{BaCu}\left(\mathrm{B}_{2} \mathrm{O}_{5}\right)$ Ceramics and their Effect on the Sintering Temperature and Microwave Dielectric Properties of $\mathrm{Ba}\left(\mathrm{Zn}_{1 / 3} \mathrm{Nb}_{2 / 3}\right) \mathrm{O}_{3}$ Ceramics. Journal of the American Ceramic Society, 89(10), 3124-3128. doi:10.1111/j.1551-2916.2006.01157.x.

18.Jiang H., Zhai J., Zhang J., Yao X. (2009): Microwave Dielectric Properties and Low-Temperature Sintering of $\mathrm{Ba}_{0.6} \mathrm{Sr}_{0.4} \mathrm{TiO}_{3}$ Ceramics. Journal of the American Ceramic Society, 92(10), 2319-2322. doi:10.1111/j.15512916.2009.03226.x.

19.Huang J., Cao Y., Hong M., Du P. (2008): Ag- $\mathrm{Ba}_{0.6} \mathrm{Sr}_{0.4} \mathrm{TiO}_{3}$ composites with excellent dielectric properties. Applied Physics Letters, 92(2), 022911. doi:10.1063/1.2836764.

20.Li, M. Yu Q., Qian K., Ji S., Du P. (2011): The Effect of $\mathrm{B}_{2} \mathrm{O}_{3}-\mathrm{Li}_{2} \mathrm{CO}_{3}$ Addition on Sintering Behavior and Dielectric Properties of $\mathrm{Ba}_{0.6} \mathrm{Sr}_{0.4} \mathrm{TiO}_{3}$ Ceramics. Advanced Materials Research, 197-198, 333-338. doi:10.4028/www.scientific. net/AMR.197-198.333.

21.Rhim S., Hong S., Bak H., Kim O. (2000): Effects of $\mathrm{B}_{2} \mathrm{O}_{3}$ Addition on the Dielectric and Ferroelectric Properties of $\mathrm{Ba}_{0.7} \mathrm{Sr}_{0.3} \mathrm{TiO}_{3}$ Ceramics. Journal of the American Ceramic Society, 83(5), 1145-1148. doi:10.1111/j.1151-2916.2000. tb01345.x.

22.Jiang H., Zhai J., Chou X., Yao X. (2009): Influence of $\mathrm{Bi}_{2} \mathrm{O}_{3}$ and $\mathrm{CuO}$ addition on low-temperature sintering and dielectric properties of $\mathrm{Ba}_{0.6} \mathrm{Sr}_{0.4} \mathrm{TiO}_{3}$ ceramics. Materials Research Bulletin, 44(3), 566-570. doi:10.1016/j.materresbull.2008.07.016.

23. Yun S.-W., Koo S.-M., Ha J.-G Koh J.-H. (2010): Influence of $\mathrm{CuO}$ Addition to $\left(\mathrm{Ba}_{0.5} \mathrm{Sr}_{0.5}\right) \mathrm{TiO}_{3}$ Ceramics on Sintering Behavior and Dielectric Properties. Ferroelectrics, 403(1), 19-25. doi:10.1080/00150191003744583.

24.Wu B., Zhang L., Yao X. (2004): Low temperature sintering of $\mathrm{Ba}_{0.6} \mathrm{Sr}_{0.4} \mathrm{TiO}_{3}$ glass-ceramic. Ceramics International, 30(7), 1757 - 1761. doi:10.1016/j.ceramint.2003.12.130.

25.Jiang H., Zhai J., Chou X., Yao X. (2010) ?. Microwave Property of Low-Temperature-Sintered $\mathrm{Ba}_{1-x} \mathrm{Sr}_{x} \mathrm{TiO}_{3}$ Ceramics with B-Li Glass Sintering Aid. Ferroelectrics, 403(1), 11-18. doi:10.1080/00150191003744492.

26.Zhang M., Wang H., Yang H., Liu W., Zhou H., Yao X. (2011): Enhanced dielectric properties of low-temperature-sintered $\mathrm{Ba}_{0.6} \mathrm{Sr}_{0.4} \mathrm{TiO}_{3}$ thick films. Journal of Electroceramics, 26, 99-104. doi:10.1007/s10832-0119634-y.

27. Valant M., Suvorov D. (2004): Low-Temperature Sintering of $(\mathrm{Ba} 0,6 \mathrm{Sr} 0,4) \mathrm{TiO}$. Journal of the American Ceramic Society, 87(7), 1222-1226. doi:10.1111/j.1151-2916.2004. tb07716.x.

28. Tick T., Peräntie J., Jantunen H., Uusimäki A. (2008): Screen printed low-sintering-temperature barium strontium titanate (BST) thick films. Journal of the European Ceramic Society, 28(4), 837-842. doi:10.1016/j. jeurceramsoc.2007.08.008

29.Kim S.-H., You H.-W., Koo S.-M., Ha J.-G., Nam S.-M., Koh J.-H., Jeong S. J. (2009): Comparative Analysis of $\mathrm{Li}_{2} \mathrm{CO}_{3}$ Doped $(\mathrm{Ba}, \mathrm{Sr}) \mathrm{TiO}_{3}$ and $\mathrm{ZnBO}$ Doped $(\mathrm{Ba}, \mathrm{Sr}) \mathrm{TiO}_{3}$ Ceramics for the Low Temperature Sintering Applications. Ferroelectrics, 382(1), 76-84. doi:10.1080/00150190902869863.

30.Wu B., Zhang L., Yao X. (2004): The effect of ZnB-Si-O addition on $\mathrm{Ba}_{0.7} \mathrm{Sr}_{0.3} \mathrm{TiO}_{3}$ by sol-gel process. Ceramics International, 30(7), 1753 - 1756. doi:10.1016/j. ceramint.2003.12.132.

31.Kim S.-H., Koh J.-H. (2008): ZnBO-doped (Ba, Sr) $\mathrm{TiO}_{3}$ ceramics for the low-temperature sintering process. Journal of the European Ceramic Society, 28, 2969-2973. doi:10.1016/j.jeurceramsoc.2008.04.034.

32.Kim S.-H., Koh J.-H. (2009): Dielectric Properties and AC Conduction of 5 wt. $\% \mathrm{ZnBO}$ Doped $(\mathrm{Ba}, \mathrm{Sr}) \mathrm{TiO}_{3}$ Ceramics for Low Temperature Co-fired Ceramics Applications. Japanese Journal of Applied Physics, 48(4), 041407. doi:10.1143/JJAP.48.041407.

33.Hilton A.D., Frost R. (1992): Recent developments in the manufacture of barium titanate powders. Key Engineering Materials, 66-67, 145-184. doi:10.4028/www.scientific. net/KEM.66-67.145.

34.Neubrand A., Lindner R., Hoffmann P. (2000): Roomtemperature solubility behavior of barium titanate in aqueous media. Journal of the American Ceramic Society, 83(4), 860-864. doi:10.1111/j.1151-2916.2000.tb01286.x.

35. Deutsches Zentrum für Luft- und Raumfahrt - Institut für Werkstoff-Forschung. Institutsbroschüre: Mikroanalytik, Metallographie und werkstoffmechanische Prüfung, http://www.dlr.de/wf/portaldata/23/resources/dokumente/ flyers/mum/mikroanalytik-metallographie-werkstoffmechanische_pruefung.pdf. Version of 12/08/07.

36. MRL Frederick Seitz Materials Research Laboratory. http:// mrl.illinois.edu/facilities/center-microanalysis-materials/ $\mathrm{cmm}$-instruments/x-ray-diffraction-xrd-and-reflectivityxrr. Version of 12/08/07.

37.DIN EN 993-1. Prüfverfahren für dichte geformte feuerfeste Erzeugnisse. Teil1: Bestimmung der Rohdichte, offenen Porosität und Gesamtporosität, 1995.

38.DIN EN 623-2. Monolithische Keramik - Allgemeine und strukturelle Eigenschaften. Teil 2: Bestimmung von Dichte und Porosität, 1993

39.Ngo E., Joshi P. C., Cole M. W., Hubbard C. W. (2001): Electrophoretic deposition of pure and $\mathrm{MgO}$-modified $\mathrm{Ba}_{0.6} \mathrm{Sr}_{0.4} \mathrm{TiO}_{3}$ thick films for tunable microwave devices. Applied Physics Letters, 79(2), 248-250. doi:10.1063/ 1.1384899 .

40.Guo H., Gao W., Yoo J. (2004): Barium strontium titanate $\left(\mathrm{Ba}_{0.7} \mathrm{Sr}_{0.3} \mathrm{TiO}_{3}\right)$ ferroelectric films produced by electrophoretic deposition. Current Applied Physics, 4(2), 385-388. doi:10.1016/j.cap.2003.11.055. 